Interpreting Lived Experience through Writing Online in a Graduate Seminar

\author{
Mary Clare Courtland \\ Lakehead University \\ Thunder Bay, Ontario, Canada
}

John Novak, Gail LaFleur, and Ken McClelland

Brock University

St. Catharines, Ontario, Canada

Steve R. Sider and Joan Shaw

University of Western Ontario

London, Ontario, Canada 


\begin{abstract}
Participants in an online doctoral seminar participated in the use of a writing strategy to explore the sociocultural contexts of their lived experience. Creating literary texts in three forms was an effective strategy in mediating participants' understanding. Each form provided a new lens through which to interpret experience. Participants functioned as an interpretive community. The final papers, autobiographical narratives, illuminated the complex relations among prediscursive experience, reflection on experience, distancing, and the iterative transformational quality of time. The online format embodied a virtual interpretive location which allowed participants to revisit texts and postings over time.
\end{abstract}

Des participants dans un cours de doctorat en ligne, ont utilisé une stratégie de rédaction leur permettant d'explorer les contextes socioculturels de leurs expériences de vie. La création de trois formes de textes littéraires s'est avèrée une stratégie efficace pour faciliter la compréhension des participants. Chaque forme littéraire a offert de nouvelle perspectives aux étudiants pour interpréter leurs expériences. Les participants dans cette communauté ont pu interpréter collectivement leurs expériences de vie. Les textes finaux, qui ont pris la forme de narratifs autobiographiques ont illustré la complexité des relations qui existent entre une expérience pré-réfléchie, la réflexion sur l'expérience, la capacité de prendre de la distance face a l'expérience. Dans ces mêmes textes on y trouve la nature réitérée et la qualitée transformative du temps. Le format en ligne a crée un endroit virtuel interprétatif qui a permis aux participants de revisiter les textes et les messages affichés dans le temps

Participantes en un seminario doctoral en línea tomaron parte en el uso de una estrategia de alfabetización para explorar los contextos socio-culturales de su propia experiencia. La creación de textos de alfabetización en tres formas fue una estrategia eficaz en la mediación del entendimiento de los participantes. Cada forma proveyó una nueva lente por la cual interpretar la experiencia. Los participantes hicieron de una comunidad interpretativa. Los trabajos finales, narrativos autobiográficos, dilucidaron las complejas relaciones entre la experiencia prediscursiva, la reflexión acerca de la experiencia, el distanciamiento, y la cualidad iterativa transformacional del tiempo. El formato en línea incorporó un lugar virtual interpretativo que permitió a los participantes re-visitar los textos y los registros a lo largo del tiempo. 


\section{Interpreting Lived Experience through Writing Online in a Graduate Seminar}

Language not only transmits, it creates or constitutes knowledge or a "reality." Part of that reality is the stance that the language implies toward knowledge and reflection, and the generalized set of stances one negotiates creates in time a sense of one's self. Reflection and "distancing" are crucial aspects of achieving a sense of the range of possible stances — a metacognitive step of huge import. (Bruner, 1986, pp. 132-133)

Support for the potential of writing as a medium for reflection on experience comes from a variety of sources. Pinar, Reynolds, Slattery, and Taubman (1995) envision “currere” as “autobiographical self-report [which] communicates the individual's lived experience as it is socially located, politically positioned, and discursively formed, while working to succumb to none of these structurings" (p. 416). Pinar and his colleagues note that both phenomenological and autobiographical research methods function to enable individuals to enter into and distance themselves from experience as they negotiate and construct meaning. Sumara (2001) describes the power of language as a medium for discovery and reflection:

Language does not exist as a veil between subjects and objects but, rather, functions to fuse together, in resymbolized relations, the tightly bound fabric of experiences that constitutes one's identity. It is the capacity to use language to not only create links among things that are present to consciousness but, as well, to things that are remembered or predicted that gives humans a unique ability to interpret the relations of past, present, and projected experience. Supported by the capacity to remember, to bear witness, and to interpret history, humans are able to engage in the imaginative acts of reconsideration and 
creative invention. (p. 18)

Sumara (1996) has contributed significantly to our understanding of the act of reading through his conceptual work on how literary texts announce commonplace locations which function as “collecting places" wherein readers' intertextual relations develop. He has developed the idea of a commonplace book as metaphor and artifact. Recently Sumara (Laidlaw \& Sumara, 2000; Sumara, 2001) has been exploring particular structured reading and writing practices to enhance readers' relations with literary texts. Laidlaw and Sumara (2000) report that the use of a commonplace book in graduate seminars provided "structures, practices, and rituals which transform time and our notions of mentorship and curriculum" (p. 9). Graduate students in the seminars read carefully selected academic and literary texts, created autobiographical texts, and shared and responded to excerpts of colleagues' texts. Laidlaw and Sumara note that “commonplace practice provides locations for inquiry into and understanding of texts, events and individual daily experiences, as teachers, learners, and whoever we might be outside the classroom" (p. 19). Interpretation was both an individual and a collective phenomenon: "Individual memories and interpretrations, captured and created in the commonplace books, were transformed into a connective tissue of history, memory, and identities" (p. 19). For Sumara, language mediates the transformation of time as individuals weave together past, present, and future (Laidlaw \& Sumara, 2000).

Smagorinsky and O'Donnell-Allen (1998) note that revisiting and reinterpreting texts through a variety of symbol systems is important to constructing meaning. As well, the artifacts and 
products generated by readers serve to mediate new thinking about the texts. The construction of meaning through language involves personal as well as cultural and social dimensions (Gambell \& Courtland, 2000; Straw \& Bogdan, 1993; Sumara, 1996). The interpretations readers place on texts are influenced by their values and beliefs (Gambell \& Courtland, 2000). Lambercane (2002) explains that the interpretive community also fulfills an important role in the construction of meaning. He notes that interaction between readers and texts is initially a "private affair in which reader and text work together to produce an interpretation" (p. 101) and that "writing other voices into this relationship helps us to extend the range of the conversation to include other members in the interpretive community" (p. 101).

Citing Janet L. Miller's (1990, cited in Pinar et al., 1995) research on autobiographical method, Pinar and his colleagues report that "the process of creating an interpretive community in which lived experience can be discovered, expressed and interpreted is one, in Miller's phase of 'creating spaces.' Such spaces must accompany the effort to understand curriculum as autobiographical text”' (p. 524).

This paper describes the use of a writing strategy implemented in an online doctoral seminar in a Joint $\mathrm{PhD}$ program to mediate the participants' understanding of the sociocultural contexts of their lived experience. Participants were invited to identify a poignant lived experience and to write about it in three literary forms. They then wrote an autobiographical narrative which reinterpreted and represented the experience within a theoretical framework. Data sources included participants' weekly postings on course readings, pieces of writing and responses, 
synthesis papers and the autobiographical narratives. The discussion illuminates participants' voices, texts, and the multitextured constructions of meaning which emerged as they explored and reflected on their experience. 


\section{Discussion}

\section{Explorations of Lived Experience}

Gail, Joan, Ken, and Steve were doctoral students in the graduate seminar. Gail is an Aboriginal scholar who teaches in a postsecondary college; Joan is a teacher-librarian in an elementary school; Ken is a lecturer at a university; and Steve is principal of a private secondary school. John and Mary Clare are instructors and researchers in Faculties of Education and were coinstructors of the seminar.

Each participant articulated a lived experience which was poignant to him/her. Gail described an experience she had had when she was hired at a university to develop an Aboriginal degree program in counselling. She explained the context of the experience in her narrative:

Two years ago, I was hired to coordinate and develop a specific Aboriginal degree program. During the first month of work I discovered that the university was not sure of the validity of the program, but encouraged me to put a proposal together to persuade and validate the potential success of the proposed program. Up to then, I had assumed that my being hired was an apparent support for program development and delivery... I immediately saw that similar programs, in the development stage, were moving merrily along with the support and attention of the university's faculty and administration... It became increasing difficult to create a degree program that met with resistance, neglect, and few current resources.

For her second piece, Gail wrote a poem which related her "frustration... with the political processes of the colonial university." In her final piece, Gail focused on her job interview, her 
resignation from the position, and the actors (colleagues) in Soap Box Writing \#3.

Ken recounted an experience which he had had as a mature student in a Master of Education program. As a graduate of a humanities program, he had anticipated engaging in spirited dialogue about intellectual ideas. Instead, in one course, he encountered three young men who wanted the graduate degree for professional reasons and showed marked disdain for intellectual inquiry. Their ridicule challenged Ken's values about university education. For his second piece, he created a poem which juxtaposed past and present, a metaphor for the present state of humanities education. His last piece was a letter to the university articulating his concerns.

Steve had grown up overseas and considered himself a " $3^{\text {rd }}$ culture kid." He felt that this position "has allowed me to look at world events from a 'bird's eye' view. I can say that I have prided myself on this apparently non-biased world view. I was wrong." Steve described a history lesson he had taught on World War II and the evils of Nazi Germany where he first became aware of his own biases:

The first time that I became aware of bringing my cultural foundations into the educative process was when I had an exchange student from Germany in my class. I was speaking in rather wide-sweeping, generalized terms about the atrocities of the German people during World War II. I did not pick up on the fact that the girl was becoming increasingly uncomfortable until another student asked a question which was directed at her feelings toward what some of the citizens of her country had done in World War II. Nothing in my text or curriculum guide had prepared me for this situation. We learn (whether 
implicitly or explicitly) that the Germans were "bad" in World War II. Without diminishing the truth that many Germans did horrible things during World War II, we must also understand that there were many other Germans who despised what the authorities were doing. The girl in my class squirmed in her seat...

Steve's initial insight and subsequent experiences led to a heightened awareness of his perspective on history: “...[I] considered whether I was teaching an accurate portrayal of history or a "western" or Canadian or "me" version. I realize that we cannot fully separate our socialization from what and how we teach. However, minimally we need to be mindful of the fact that our culture is wound up with what, why, and how we teach..." For his second and third pieces, Steve wrote a poem and a short story/parable.

Joan had become a librarian after twenty-five years as a classroom teacher and music specialist. Her personal narrative, All that glitters is not gold, recounted her initial seduction by technology and her growing realization of the many issues which emerged as she attempted to implement an Information Technology [IT] program in her school. Joan concluded her narrative by articulating the issue: "Four years have passed and I have struggled tremendously with the many ramifications of integrating IT with information literacy skills (as research skills are now called). I am determined to work this through to my satisfaction. The reading and thinking we are doing in this course are going to help me achieve this goal." Joan's second piece was a reader's theatre which described in multiple voices her initial enthusiasm, growing disillusionment, and, ultimately, a moderate approach to IT. Her final piece from the point of view of a colleague about Joan's ideas on IT: “Last week I had a staff room encounter with a teacher I highly respect. 
I thought we had had quite a civilized discussion, although emotionally heated, about using librarian-created web sites to connect parents to what was going on with student research projects in the library. I tried to put myself in her shoes with [my] literary text."

In exploring the ways in which the writing strategy mediated participants' understanding of their lived experiences, three dimensions emerged. Firstly, writing in three different forms enabled participants to access multiple stances or perspectives on the lived experience. Secondly, participants perceived these texts as literary texts which opened spaces for interpretation or reconsideration of the experience. Thirdly, the interpretive community contributed to private and social construction of meaning.

Although the choice of forms in which to articulate lived experience was optional, all participants begin by creating a personal narrative. These narratives seemed to function as a means of recounting and reflecting on a poignant experience. The selection of poetry or reader's theatre as form enabled participants to achieve distance from the initial iteration of the experience. Gail's poem, for example, situates her personal experience in the academy within the collective history and current status of Aboriginal peoples:

\section{Buffalo breakfast}

Tick...tock...tick....tock...

Are we becoming EXTINCT?

\section{Countdown genocide...}

\section{Are we all to forget}




\begin{abstract}
Anishinabe
Kinomaagewin - the teachings?

Turtle Island: 120 Million to

$660,000 \ldots . .559,000 \ldots . .558,000 \ldots . .557,000 \ldots$

Registered Indians

Bezhig, niizh, nswi-One (little)...

Two (little)...Three (little Indians)
\end{abstract}

Our languages are almost gone, but the respect for knowing what is dbwe

-true remains strong.

WAIT. WAIT. WAIT!

You must WAIT.

We couldn't possibly cover that.

We don't have the time, $\$$, or interest

NOW!

(Disinterest, discomfort, disapproval, disdain, disEASE,

disrespected...disappeared!!!)

THERE ARE MORE IMPORTANT THINGS TO KNOW.

If we do it for you, we'll have to do it for everybody.

You have NO STATUS HERE in your homeland.

I don't see you, so that makes you invisible...

The burning questions are flames of an ishkode-hot fire.

What Edge are you selling today? 
What's on the educational menu?

And, who is the cook for today?

Can you please take our order?

No, we are too busy right now. Can you come back, LATER?

Please...pretty Please?!

I'd like to feast on traditional Aboriginal fare, but I never

was encouraged to eat Bizhiki wiiyaas-buffalo for

breakfast.

AGAIN, the speaker talks to us, saying, "McDonald's, Can I take your order?"

Gail's reference to the "burning questions" alludes to the future.

The third piece of writing provided participants with another lens on the experience. In one journal posting, Steve commented on the effectiveness of the strategy in mediating understanding of one's lived experience:

When I first heard how we would be describing an experience in three literary forms I will admit that I was skeptical. The first assignment went fine and I felt that I was able to develop a new understanding of an "old" experience. When it came time to write the second piece, I approached it grudgingly. I felt that I would just be re-phrasing the same experience. As well, the form bothered me. I had absolutely no training in poetry (grade 11 English being the last time I was required to write in this format) and little desire to learn! However, as I started to sketch some thoughts, I discovered that certain concepts I was writing about became clearer in my mind. Specifically, I think my sense of empathy for the student who was the centre of my experience became heightened. I'm not sure if it 
was due to writing in a different form or because the form was poetry. As I have worked on the $3^{\text {rd }}$ writing experience, I have noted that once again, a different form of writing leads to a variance in my perspective.

Writing in three forms enabled participants to access multiple stances on their experiences, to enter into and distance themselves from the experiences (Pinar et al., 1995). The use of poetry reader's theatre enabled each to consider the broader picture, the sociocultural context, in which the experience was situated.

Frequently, in language education, the terms literature and literary texts are used to describe aesthetic works published by "others." Texts composed by students are referred to as pieces of writing or samples. Joan described the writing generated by participants as "literary texts which created spaces for interpreting experience. Because I have a propensity toward musical endeavour and I love the power of literature, mediating understanding through literary texts has seemed quite a natural activity." Joan cited Frye's (1963) observations on the power of literature to heighten one's understanding of experience:

In The Educated Imagination, Northrop Frye writes that "literature gives us an experience that stretches us vertically to the heights and depths of what the human mind can conceive." I think that our writing of literary texts is helping us do that. Later Frye writes: "Our impressions of human life are picked up one by one, and remain for most of us loose and disorganized. But we constantly find things in literature that suddenly coordinate and bring into focus a great many such impressions... (p. 42).

Creating and reading literary texts thus opened spaces for the discovery, expression, and 
interpretation of experience. These texts enabled participants to reinterpret and represent experience (Frye, 1963; Sumara, 2001) within a sociocultural context.

Course readings as well as the writing and discussion postings entered on the website each week provided a springboard for discourse among the members of the interpretive community. The work of the interpretive community was evident in the ongoing dialogue among participants. In this collaborative online environment, participants responded to others' literary texts, related personal experiences evoked by the texts, referred to literature and course readings, and recommended professional books and articles to one another. The website functioned as a virtual interpretive location, a collecting place for the ideas and interpretations being negotiated within the interpretive community. Interpersonal and intertextual relations evolved over time against the backdrop of course readings. For example, the lived experience that Gail articulated was deeply rooted in historical, cultural, and personal contexts. Gail facilitated the group discussion online of Smith's (1999) Decolonizing methodologies: Research and indigenous peoples. In her introduction, Gail explained Smith's perspective and her "burning questions":

...Understanding the cultural values and beliefs between Native and non-Native peoples, is seen as imperative to understanding these experiences of intellectual neglect for Indigenous students. Decolonizing methodologies resists instead of complies to take a closer look at the way school knowledge is organised, the implications of the hidden curriculum, and "difference" representations in curriculum and research. The caution is that present school organisation has "serious implications for indigenous students as well as for other minority ethnic groups." For some, the challenge will be to experience the 
role of "the other" and in doing so, challenge themselves in understanding how our indigenous and minority students can be treated with more humanity and respect. How does it feel to "separate?" Are there other experiences with this feeling? How can we respect our culturally diverse students, so we can connect to the ideology of their "wholeness?"

Welcome to the world of Indigenous issues in education. Today, these issues are also based upon the principles of self-determination, decolonization and social justice. This book is a rare find, in that, it attempts to promote the political identifies of Indigenous peoples as learners and researchers and a society which respects the culture of the First Peoples of these lands.

Miiqwech.

Joan's synthesis paper included reference to ideas that Gail shared with the group: “...So much depends on understanding curriculum as political text. As Gail Lafleur pointed out, each of us should make use of his/her political voice. I am more aware of the importance of claiming my voice as a teacher and a student. However small, I can make a difference.”

After Steve had created his literary texts, he reflected on the role of the interpretive community in his writing:

I have gained from the reactions/reflections of others to my writing as well as in their own writings. I am amazed at the ability of the written word to communicate: The fact that others in the class have been gracious with my written thoughts has been greatly appreciated. Actually, I've been surprised at the overwhelmingly positive nature of the 
correspondence that we have had. It has helped with putting "thoughts on the table" which otherwise may not have been "played." However, I think we have to be careful that we remain critical and provide more than "surface" comments...

Steve wondered, too, about whether a face-to-face seminar would have presented a different forum for response than the virtual website. Elsewhere he observed that one of the disadvantages of posting online was the time delay before others read and responded to his writing. In a weekly face-to-face seminar, it is likely that participants would have read their texts to one another and the listeners would have responded orally. The online asynchronous format enabled participants to read, reread, reflect, and respond recursively to texts. The format created potential spaces for interpretation and reinterpretation in the same way that literature enables readers to revisit texts and/or portions of texts during an initial reading as well as over time. The virtual interpretive location is reminiscent of Laidlaw's and Sumara's (2000) construct of the commonplace book as metaphor and artifact. As well, the interpretive community involved both personal and social constructions of meaning into which were woven multiple voices (Laidlaw \& Sumara, 2000; Labercane, 2002). 


\section{Interpretations of Lived Experience}

Writing about a lived experience across three forms enabled the participants to describe and reflect on their experiences through different voices and perspectives. The autobiographical narrative served as a vehicle for engagement with and distancing from the experience, thus enabling the participants to examine critically the sociocultural contexts in which their experiences were situated. Ken's definition of experience and its relation to reflection on experience are insightful: "In exploring Dewey's theory of art and aesthetic experience, I came to an important aspect of Dewey's thinking on experience. It had to do with the notion of pervasive quality... any description or attempt at description is already a step removed from the essential 'isness' of qualitative experience. It has 'already flowed by' by the time we say anything about it." He explained that ...we cannot, that is, say anything of its immediacy, for its immediacy, as I mentioned above, is something had or felt, wholly pre-reflective and thus prediscursive. It is that quality of immediate experience which is irreducible and indescribable. Yet if this were the be-all-and-end-all of experience, we would find ourselves in no vital connection to our environment, receiving no more than a meaningless barrage of sensory impressions. We can and inevitably must say something out of the pervasive quality that flows in and through experience, but what we say is a reflection of how we have defined, discriminated, and situated ourselves in relation to any particular experience.

Thus, experience itself is prereflective and prediscursive. Language is the medium through which human beings reflect on and make sense of lived experience (Bruner, 1986; Sumara, 2001). "Currere" (Pinar et al., 1995, p. 46) involves the process of situating or positioning one's 
reflection on experience within a theoretical framework.

The participants in the seminar practiced currere in different ways. For example, during the seminar, the participants were not aware that Ken's mother was seriously ill. In his paper, Ken wove this deeply-felt experience into a masterful discussion of the historical roots which have led to the current state of the humanities in the modern university:

...as I attempt to situate this [lived] experience within a personal/professional narrative I find myself carried winged-like to an experience that presently I am undergoing - the terminal illness of my mother. In what way does this deeply personal experience bear on the experience that occurred six or seven years ago at University? I am amidst a personal crisis. My profound felt connection to my mother comes welling to the surface of my consciousness. Experiential depth collides with experiential presence. I realize in these profoundly painful moments, that I reside still and always in the womb of my mother's care and compassion. The filter through which my narrative is distilled in thus one of care, for it is care, deep and enduring care - my mother's care - that is the source of so much of myself, of that personal matrix out of which I interpret my experiences. As I grieve the imminent death of my mother, I find a voice of hope for another very ill loved one - my/the university. My narrative will thus trace the deeper viscera of an experience. It will manifest an expression of grief and hope for that which I love - my mother, my institution.

Ken's lived experience was for him a manifestation of problems in the direction which the humanities have taken over time. The integration of past, present, and future within a matrix of 
care support Laidlaw's and Sumara's (2000) conception of the transformational quality of time.

Gail integrated her lived experience of attempting to develop a degree program for Aboriginals and her literary texts into a powerful theoretical discussion of the origins of the "colonial university" (Smith, 1999, p. 65) and the imperialistic assumptions, worldview, and practices which perpetuate the status quo and the marginalization of Indigenous ways of knowing and experiencing. In concluding her paper, she reflected on the role of autobiographical narratives in coming to understand the sociocultural and sociopolitical contexts of lived experience:

Autobiographical narratives... allow for self-reflection, meaning making, and sharing... Utilizing this process to understand our social identities as those who struggle and those who do not, enables liberation and recovery of our collective histories one community a time, one individual at a time, and one day at a time. It is through the microcosm that change will occur to the macrocosm and vice versa. It is through our understanding as socio-political and socio-cultural beings that we can reclaim our identity and history as indigenous peoples and indigenous professors working in the academy...

Conclusion

This paper describes the use of a writing strategy to mediate graduate students' understanding of the sociocultural contexts in which their lived experience was situated. The context for the graduate seminar was virtual and asynchronous. The virtual environment allowed participants to read, write, and revisit their own and others' texts over time.

Participants wrote about the experience in three literary forms. These forms enabled them to 
explore lived experience from multiple perspectives. The participants perceived the texts which they created as literary texts which, like literature, opened spaces for interpretation. The interpretive community provided support for the interpretation and reinterpretation of ideas.

In interpreting lived experience, the autobiographical narrative served as a means for engagement with and distancing from the lived experience, thus enabling participants to examine critically the theoretical contexts in which experience was situated. With the exception of the sequential development of the literary texts, the interpretive process was recursive. As Smagorinsky and O'Donnell-Allan (1998) point out, creating and revisiting artifacts leads to new thinking about these texts. The division of the process into exploring and then interpreting lived experience was arbitrary and was intended as a means to illuminate how the participants engaged in reflections on prediscursive experience and distancing from the experience. The final papers demonstrated the transformational quality of time (Laidlaw \& Sumara, 2000). This construct is insightful in appreciating the complex dimensions of practicing currere.

The use of this writing strategy then, suggests one method to enable human beings to reflect on and reconsider experience, or as Sumara (2001) so eloquently describes this phenomenon in his discussion on the power of language: "to fuse together, in resymbolized relations, the tightly bound fabric of experiences that constitutes one's identity..." (p. 18). 


\section{References}

Bruner, J. (1986). Actual minds, possible worlds. Cambridge, MA: Harvard University Press.

Frye, N. (1963). The educated imagination. Concord, ON: Anansi.

Gambell, T. J., \& Courtland, M. C. (2000). A framework for reader response. In M. C. Courtland and T. J. Gambell (Eds.), Young adolescents meet literature: Intersections for learning (pp. 46-96). Vancouver, BC: Pacific Educational Press.

Labercane, G. (2002). Between readers and texts: The work of the interpretive community. In M. Hunsburger and G. Labercane (Eds.), Making meaning in the response-based classroom (pp. 99-115). Boston, MA: Allyn \& Bacon.

Laidlaw, L., \& Sumara, D. (2000). Transforming pedagogical time. Journal of Curriculum Theorizing, 16(1), 9-22.

Pinar, W. F., Reynolds, W. M., Stattery, P., \& Taubman, P. M. (1995). Understanding curriculum: An introduction to the study of historical and contemporary curriculum discourses. New York, NY: Peter Lang.

Shaw, J. (2003). Navigating a raging river: A Canadian teacher librarian's experience implementing information technology. Libres, 13(2). Retrieved September 20, 2003, from http://libres.curtin.edu.au

Smagorinsky, P., \& O’Donnell-Allen, C. (1998). Reading as mediated and mediating action: Composing meaning for literature through multimedia interpretive texts. Reading Research Quarterly, 33(2), 198-226.

Smith, L. T. (1999). Decolonizing methodologies: Research and Indigenous peoples. London, UK: Zed Books.

Straw, S. B., \& Bagdon, D. (Eds.). (1993). Constructive reading: Teaching beyond 
communication. Portsmouth, NH: Boynton, Cook.

Sumara, D. J. (2001). Creating commonplaces for interpretation: Advancing literary anthropology as a research method. Paper presented at the annual conference of the Canadian Society for the Study of Education, Quebec.

Sumara, D. J. (1996). Private readings in public. New York, NY: Peter Lang. 


\section{Biographical Statement}

Mary Clare Courtland, Lakehead University, teaches and conducts research in curriculum and language education. John Novak, Brock University, is a Deweyan scholar. Gail Lafleur, an instructor at a postsecondary college, and Ken McLelland, a lecturer in philosophy, are doctoral candidates at Brock University. Steve Sider, a secondary school principal, and Joan Shaw, an elementary school librarian, are doctoral candidates at the University of Western Ontario. 


\section{Acknowledgment}

Mary Clare Courtland would like to thank Dr. Rebecca Luce-Kapler, Queen's University, for describing how she integrates writing assignments into her doctoral seminars. Our conversation at the annual conference of CSSE in 2001 was the spark which led to the development of the writing strategy. 